Arq. Bras. Med. Vet. Zootec., v.70, n.3, p.830-836, 2018

\title{
Avaliação de dietas na reprodução de calopsitas e parâmetros reprodutivos
}

[Diet assessment in cockatiels reproduction and reproductive parameters]

\author{
V.D.L. Assis ${ }^{1}$, T.S.G. Carvalho ${ }^{2}$, C.E.P. Saad $^{2}$, E.S. Miyagi ${ }^{1}$, M.P. Gionbelli ${ }^{2}$ \\ ${ }^{1}$ Universidade Federal de Goiás - UFG - Goiânia, GO \\ ${ }^{2}$ Universidade Federal de Lavras - UFLA - Lavras, MG
}

\section{RESUMO}

As calopsitas são consideradas aves monogâmicas, atingem a maturidade sexual aos 12 meses, com postura variando entre três a sete ovos. São classificadas como granívoros, embora alguns estudos tenham demonstrado uma grande diversidade nos hábitos alimentares. Este trabalho foi realizado em caráter investigativo, com o objetivo de comparar o efeito de dietas na reprodução de calopsitas, assim como efetuar um levantamento dos parâmetros reprodutivos da espécie. O experimento foi feito na Universidade Federal de Lavras. As análises estatísticas foram realizadas utilizando-se o GLM do SAS (Statistical Analysis System, Cary, NC, USA). A variável ordem de postura apresentou significância $(\mathrm{P}<0,1)$ com as variáveis espessura da casca, peso do ovo e tempo de eclosão. A variável peso do ovo apresentou significância $(\mathrm{P}<0,1)$ com as variáveis, ordem de postura e largura do ovo. Os resultados encontrados neste estudo suportam a conclusão de que a dieta formulada conseguiu suprir as necessidades nutricionais das calopsitas na fase reprodutiva, não afetando a qualidade e a fertilidade dos ovos.

Palavras-chave: Nymphicus hollandicus, ovos, postura, psitacídeos

\begin{abstract}
Cockatiels are monogamous birds that reach sexual maturity at twelve months, with posture ranging from three to seven eggs. They are classified as granivores, although some studies have shown a great diversity in eating habits. This work was performed in investigative character, in order to compare the effect of diet on reproduction of cockatiels and perform a survey of reproductive parameters of the species. The experiment was conducted at the Federal University of Lavras. Statistical analyzes were performed using the SAS GLM (Statistical Analysis System, Cary, NC, USA). The variable order posture showed significance $(P<0.1)$ with the variables, shell thickness, egg weight and time of hatching. The variable egg weight showed significance $(P<0.1)$ with the variables posture order and width of the egg. The results found in this study support the conclusion that the formulated diet was able to satisfy the nutritional needs of the calopsitas in the reproductive phase, not affecting the quality and the fertility of the eggs.
\end{abstract}

Keywords: eggs, Nymphicus hollandicus, posture, parrots

\section{INTRODUÇÃO}

A ordem Psittaciformes compreende, em média, 350 espécies que ocorrem naturalmente nas regiões central e sul da América, Austrália e Pacífico Sul, África e sul da Ásia (Christidis et al., 1991) e são divididas em três famílias, Psittacidae (araras, papagaios, periquitos, maritacas), Nestoridae (kea, kaka, kapo) e
Cacatuidae (cacatuas, calopsitas). As aves da família Cacatuidae se distinguem pela presença de uma crista de penas eréteis na cabeça e pela ausência, nas penas, de estrutura esponjosa responsável pela produção das cores verde e azul - "Dyck texture" (DYCK, 1971, citado por Somenzari, 2011). Segundo White et al. (2011), atualmente, são aceitas 21 espécies de cacatuas, as quais diferem entre si principalmente pela coloração da plumagem.

Recebido em 28 de março de 2017

Aceito em 18 de abril de 2017

E-mail: nessinhadany@yahoo.com.br 
As calopsitas (Nymphicus hollandicus) são classificadas como granívoros, embora alguns estudos tenham demonstrado uma grande diversidade nos hábitos alimentares, como grãos, flores, frutos, brotos e folhas e insetos (Torloni, 2001; Ullrey et al., 1991). Sua alimentação em cativeiro é baseada principalmente em mistura de sementes, sendo geralmente administrada em excesso, o que pode gerar problemas de saúde devido ao fato de as aves serem seletivas. Essa seletividade se deve à riquíssima quantidade de papilas gustativas, que variam em torno de $300 \mathrm{a}$ 400 (Allgayer e Cziulik, 2007; Marques et al., 2009). Como forma de minimizar essa seletividade e o desbalanço nutricional, utilizamse rações fareladas, peletizadas ou extrusadas.

A pouca disponibilidade de alimentos comerciais específicos para psitacídeos é um dos entraves na criação de aves ornamentais, uma vez que grande parte das rações é importada. Dessa forma, faz-se necessário o desenvolvimento de boas rações nacionais, que atendam economicamente ao criador e que, primariamente, atendam às necessidades nutricionais e às preferências de palatabilidade das aves que as consumirão (Saad, 2007; Machado e Saad, 2000).

As calopsitas são consideradas aves monogâmicas, que formam casais por toda a vida, tendo a ligação reforçada pelo comportamento de realizar limpeza no companheiro (Forshaw e Cooper, 1981). Em média, atingem a maturidade sexual aos 12 meses, com postura variando entre três e sete ovos, sendo um ovo por dia ou em dias alternados, podendo chegar até 25 ovos por ciclo reprodutivo (Torloni 1991; Saad, 2003; Ubuka e Bentley, 2011).

Em revisão, foi possível observar a escassez de estudos publicados que envolvessem parâmetros reprodutivos de calopsitas e que avaliassem a influência da dieta nesses parâmetros, o que demonstra a necessidade de mais pesquisas voltadas para essa área.

Este trabalho foi realizado em caráter investigativo, com o objetivo de comparar o efeito de dietas na reprodução de calopsitas, assim como realizar um levantamento dos parâmetros reprodutivos da espécie.

\section{MATERIAL E MÉTODOS}

O experimento foi realizado no Setor de Animais Selvagens do Departamento de Zootecnia (DZO) da Universidade Federal de Lavras (UFLA). Todos os procedimentos experimentais seguiram as diretrizes dos princípios de bem-estar animal de acordo com a Comissão de Ética no Uso de Animais da Universidade Federal de Lavras (Processo n⿳003/15).

Dez casais de calopsitas foram utilizados, com idade aproximada de dois anos e quatro meses, sendo cada casal alojado em uma gaiola própria para reprodução com 85 x $40 \quad$ x $45 \mathrm{~cm}$ (comprimento, profundidade, altura). Após um período de sete dias de adaptação às novas instalações e às dietas experimentais, cada gaiola recebeu um ninho de 35 x 20 x $20 \mathrm{~cm}$ (comprimento, altura, largura), dando início à fase de reprodução.

Após a adaptação, dois tratamentos alimentares foram aplicados às calopsitas. Esses tratamentos consistiram em dois tipos de ração: ração comercial (Tab. 1) própria para psitacídeos de pequeno porte e ração experimental (Tab. 2). Na Tab. 3, é apresentada a composição das rações. A ração experimental foi formulada seguindo as exigências nutricionais de poedeiras e de psitacídeos em manutenção, sendo calculada e avaliada com auxílio do software Super Crac 5.7 Master, visando atender às exigências nutricionais das aves, além da utilização de ingredientes básicos.

As aves foram alimentadas ad libitum, uma vez ao dia, às sete horas, durante toda a fase experimental. Para o cálculo do consumo de alimento, as rações foram pesadas no início e no final de cada semana, contabilizando-se as sobras do comedouro e o desperdício (ração jogada para fora do comedouro).

Foram quantificados os seguintes parâmetros reprodutivos: postura, peso do ovo, período de incubação, eclosão dos ovos, tamanho dos ovos e espessura da casca dos ovos após a eclosão. Durante o período da postura, os ovos foram devidamente identificados por ordem de postura, medidos e pesados de 48 em 48 horas até a eclosão, com auxílio de um paquímetro digital, fita métrica e balança analítica. Após eclosão, mensurou-se a espessura da casca dos ovos e, no $10^{\circ}$ dia após a postura, realizou-se ovoscopia. 
Assis et al.

Tabela 1. Níveis de garantia e composição percentual e calculada das dietas experimentais formuladas

\begin{tabular}{ccc}
\hline & \multicolumn{1}{c}{ Ração comercial (\%) } & Ração formulada (\%) \\
\hline Proteína bruta & 16,00 & 16,14 \\
Matéria fibrosa & 5,00 & 0,69 \\
Fósforo & 0,60 & 10,87 \\
Extrato etéreo & 6,50 & 1,03 \\
Cálcio & 1,60 & \multicolumn{1}{c}{ Composição básica } \\
\hline & & \multicolumn{1}{c}{ Milho*, aveia floculada, soja integral extrusada**, farelo de } \\
& soja**, óleo de soja refinado*, aromatizante, fosfato bicálcico, \\
& calcário calcítico, cloreto de sódio (sal comum), sulfato ferroso, \\
& sulfato de cobre, sulfato de manganês, óxido de zinco, iodato de \\
& cálcio, selenito de sódio, vitamina A, vitamina D, vitamina E, \\
& menadiona bisulfito de sódio, tiamina (vitamina B1), riboflavina \\
& (vitamina B2), piridoxina (vitamina B6), vitamina B12, niacina, \\
& pantotenato de cálcio, ácido fólico, biotina, DL-metionina
\end{tabular}

O experimento foi conduzido em delineamento inteiramente ao acaso, constituído de cinco repetições, tendo a gaiola como unidade experimental.

As médias dos tratamentos foram comparadas por meio de análise de variância, realizada utilizando-se o procedimento GLM do SAS (Statistical Analysis System, Cary, NC, USA), adotando-se $10 \%$ como nível crítico de probabilidade para ocorrência do erro tipo I. Quando pertinente, os coeficientes de correlação foram estimados usando-se correlação de Pearson. Funções para descrever a relação entre variáveis correlacionadas foram estimadas utilizando-se o GLM do SAS (Statistical Analysis System, Cary, NC, USA).

\section{RESULTADOS E DISCUSSÕES}

Os dados de status dos ovos, proporção dos ovos, qualidade dos ovos e consumo de ração são apresentados na Tab. 2. Em relação à postura dos ovos viáveis, verificou-se que não houve diferença significativa $(\mathrm{P}=0,613)$ entre os tratamentos. $\mathrm{O}$ consumo de ração na fase de prépostura sofreu efeito $(\mathrm{P}=0,015)$ em relação aos tratamentos.

Tabela 2. Status dos ovos, proporção dos ovos, qualidade dos ovos e consumo (g) de ração por casais de calopsitas (Nymphicus hollandicus) durante a fase reprodutiva

\begin{tabular}{|c|c|c|c|c|}
\hline \multirow{2}{*}{ Variável } & \multicolumn{2}{|c|}{ Tratamento } & \multirow{2}{*}{ EPM } & \multirow{2}{*}{ P-valor } \\
\hline & Comercial & Formulada & & \\
\hline \multicolumn{5}{|c|}{ Produção média de ovos por casal } \\
\hline Viáveis & 2,80 & 3,20 & 0,54 & 0,613 \\
\hline Não viáveis* & 1,60 & 1,00 & 0,36 & 0,273 \\
\hline \multicolumn{5}{|l|}{ Viabilidade (\%) } \\
\hline Viáveis & 61,60 & 74,60 & 10,73 & 0,416 \\
\hline Não viáveis & 38,40 & 25,40 & 10,73 & 0,416 \\
\hline Fertilidade (\%) & 85 & 75 & 0,09 & 0,4513 \\
\hline \multicolumn{5}{|l|}{ Consumo $(\mathrm{g})$} \\
\hline Pré-postura & 136,82 & 99,60 & 8,53 & 0,015 \\
\hline Pós-postura & 101,54 & 107,57 & 2,70 & 0,153 \\
\hline
\end{tabular}

*ovos não embrionados, quebrados e com morte embrionária; EPM= erro-padrão da média. 
Gowland (2014), ao avaliar o efeito de rações peletizadas tradicional e orgânica na reprodução de papagaios (Amazona aestiva, Amazona oratrix, Amazona o.ochrocephala e Amazona o. parvipes), relatou uma taxa de $51 \%$ de ovos fecundados e $22 \%$ de morte embrionária. O mesmo autor cita que estudos realizados por Enkerlin-Hoefflich (1995) com espécies de Amazonas do nordeste do México, encontraram uma média de $10 \%$ de ovos não eclodidos, por infertilidade e morte embrionária.

Hange (1994), em estudos com duas espécies de psitacídeos, uma Amazona (green cheek, lilac crown, blue crown, mealy, yellow front, double yellow, yellow nape, blue front, tucuman, orange wing, red lored , salvin's) e outra não Amazona (black-headed caique, bronze-wing pionus, hawk headed, blue headed pionus, maximillian pionus, derbyan, alexandrian, hahn's macaw, nanday conure, white crown pionus, austral conure), avaliou o efeito de duas dietas comerciais na reprodução e obteve uma taxa de $28,6 \%$ de ovos inférteis e $16 \%$ de ovos férteis para a espécie Amazona e de $19,5 \%$ de ovos inférteis e a mesma taxa para ovos férteis para as espécies não Amazona.
Saad et al. (2007), em trabalhos realizados com papagaios-verdadeiros (Amazona aestiva), encontraram dados referentes ao consumo (média de 22,04g com um mínimo de 16,93g e um máximo de $26,80 \mathrm{~g}$ ) e citam que os valores encontrados são mais altos que os valores encontrados por Carciofi (1996) para papagaios verdadeiros (mínimo de 12,40 e máximo de $19,1 \mathrm{~g}$ por ave dia).

Nas Tab. 3, 4 e 5, são apresentados dados referentes aos parâmetros reprodutivos de calopsitas, os quais podem ser importantes no estabelecimento de manejo das aves em cativeiro, tanto em criatórios conservacionistas quanto comerciais, e de manejo das aves em vida livre, com possíveis extrapolações para a gestão de muitos psitacídeos.

Os dados referentes às médias de mínimos quadrados de características de ovos de calopsitas à incubação, em função do status de viabilidade durante a incubação, estão apresentados na Tab. 3. Foram observadas diferenças $(\mathrm{P}<0,1)$ para peso, largura do ovo e ordem de postura em relação ao status dos ovos.

Tabela 3. Médias de mínimos quadrados \pm erro-padrão das médias de características de ovos de calopsitas (Nimphicus hollandicus) à incubação, em função do status de viabilidade durante a incubação

\begin{tabular}{|c|c|c|c|c|c|}
\hline \multirow[b]{2}{*}{$\begin{array}{l}\text { Variáveis à } \\
\text { incubação }\end{array}$} & \multicolumn{4}{|c|}{ Status dos ovos na incubação } & \multirow[b]{2}{*}{ Valor $\mathrm{P}$} \\
\hline & $\begin{array}{l}\text { Viáveis } \\
(n=30)\end{array}$ & $\begin{array}{c}\text { Morte } \\
\text { embrionária } \\
(n=10)\end{array}$ & $\begin{array}{c}\text { Não } \\
\text { embrionados } \\
(\mathrm{n}=1)\end{array}$ & $\begin{array}{l}\text { Quebrados } \\
\quad(n=2)\end{array}$ & \\
\hline Peso do ovo (g) & $5,826 \mathrm{a} \pm 0,083$ & $5,588 \mathrm{~b} \pm 0,108$ & $5,387 \mathrm{~b} \pm 0,285$ & $5,787 \mathrm{ab} \pm 0,211$ & 0,070 \\
\hline $\begin{array}{l}\text { Largura do ovo } \\
(\mathrm{mm})\end{array}$ & $20,174 \mathrm{a} \pm 0,009$ & $19,944 b \pm 0,125$ & $19,362 b \pm 0,346$ & $19,904 \mathrm{ab} \pm 0,254$ & 0,043 \\
\hline $\begin{array}{l}\text { Comprimento do } \\
\text { ovo (mm) }\end{array}$ & $25,448 \pm 0,375$ & $25,866 \pm 0,445$ & $25,669 \pm 1,037$ & $25,826 \pm 0,792$ & 0,679 \\
\hline $\begin{array}{l}\text { Espessura da casca } \\
\qquad(\mathrm{mm})\end{array}$ & $0,511 \pm 0,030$ & $0,516 \pm 0,035$ & $0,446 \pm 0,082$ & $0,534 \pm 0,062$ & 0,830 \\
\hline Ordem de postura $^{1}$ & $2,600 \pm 0,236$ & $3,400 \pm 0,409$ & - & - & 0,098 \\
\hline
\end{tabular}

O aumento do peso do ovo pode ser explicado devido ao desenvolvimento do embrião ao longo da incubação. Segundo Mesquita (2011), nessa fase, ocorre a diferenciação celular. Até o quarto dia, ocorre intensa multiplicação celular, diferenciação das estruturas e definição da espécie, e do quinto ao $18^{\circ}$ dia, o embrião tem um intenso crescimento (hipertrofia celular).
Segundo Fasenko et al. (1992), o folículo maduro do primeiro ovo de uma sequência de postura permanece no ovário e no oviduto por mais tempo que os folículos subsequentes, o que influencia na fertilização, na viabilidade e no estágio de desenvolvimento embrionário no momento da postura. Os mesmos autores, em estudos realizados com aves, concluíram que 
os primeiros ovos apresentaram maior fertilidade em relação aos subsequentes, o que, segundo os autores, difere dos resultados encontrados por Bacon e Nestor (1979), os quais relataram que o primeiro ovo da sequência teve significativamente menor fertilidade, eclodibilidade e uma maior incidência de mortalidade embrionária, em sete dias de incubação, do que os ovos subsequentes. Em contraste, Robinson et al., (1991) encontraram diferenças significativas na fertilidade ou na viabilidade dos ovos entre o primeiro e os ovos subsequentes de uma sequência de postura.

Na Tab. 4, são apresentados os coeficientes de correlação entre as variáveis. A variável ordem de postura apresentou significância $(\mathrm{P}<0,1)$ com as variáveis, espessura da casca, peso do ovo e tempo de eclosão. A variável peso do ovo apresentou significância $(\mathrm{P}<0,1) \quad$ com as variáveis ordem de postura e comprimento do ovo. O consumo pré-postura apresentou significância $(\mathrm{P}<0,1)$ com as variáveis largura do ovo e comprimento do ovo.

As equações de regressão para peso do ovo, espessura da casca, comprimento do ovo e dias para eclosão são apresentadas na Tab. 5. O peso do ovo e dias para eclosão são inversamente proporcionais à ordem de postura.

Tabela 4. Correlação de Pearson entre espessura da casca, ordem de postura, largura do ovo, peso do ovo, comprimento do ovo, tempo de eclosão e consumo pré-postura de calopsitas (Nymphicus hollandicus), com o valor de significância entre parênteses, com $\mathrm{P}<0,1$

\begin{tabular}{|c|c|c|c|c|c|c|}
\hline & $\begin{array}{l}\text { Ordem de } \\
\text { postura }\end{array}$ & $\begin{array}{l}\text { Largura do } \\
\text { ovo (mm) }\end{array}$ & $\begin{array}{l}\text { Peso do } \\
\text { ovo (g) }\end{array}$ & $\begin{array}{l}\text { Comprimento } \\
\text { do ovo }(\mathrm{mm})\end{array}$ & $\begin{array}{l}\text { Tempo } \\
\text { de } \\
\text { eclosão }\end{array}$ & $\begin{array}{l}\text { Consumo } \\
\text { pré-postura }\end{array}$ \\
\hline $\begin{array}{l}\text { Espessura da } \\
\text { casca (mm) }\end{array}$ & $0,3452 *$ & 0,0512 & $-0,1830$ & $-0,1886$ & 0,2313 & $-0,0959$ \\
\hline $\begin{array}{l}\text { Ordem de } \\
\text { postura }\end{array}$ & - & $-0,2766$ & $-0,3943 *$ & $-0,2540$ & $-0,3189^{*}$ & $-0,2952$ \\
\hline $\begin{array}{l}\text { Largura do ovo } \\
(\mathrm{mm})\end{array}$ & - & - & $0,4214^{*}$ & 0,5128 & 0,2274 & $0,4167^{*}$ \\
\hline Peso do ovo (g) & - & - & - & $0,5227 *$ & $-0,0132$ & 0,4302 \\
\hline $\begin{array}{l}\text { Comprimento } \\
\text { do ovo (mm) }\end{array}$ & - & - & - & - & $-0,1672$ & $0,6791 *$ \\
\hline $\begin{array}{l}\text { Tempo de } \\
\text { eclosão }\end{array}$ & - & - & - & - & - & $-0,1672$ \\
\hline $\begin{array}{c}\text { Consumo pré- } \\
\text { postura }\end{array}$ & - & - & - & - & - & - \\
\hline
\end{tabular}

Tabela 5. Equações de regressão das características de ovos de calopsitas (Nymphicus hollandicus) à postura em função do status de viabilidade durante a postura

\begin{tabular}{ccc}
\hline Variável & Função ajustada & $\mathrm{r}_{\mathrm{xy}}$ \\
\hline Peso do ovo $(\mathrm{g})$ & $\hat{\mathrm{y}}=6,02-0,082 \times$ ordem de postura & 0,393 \\
Espessura da casca $(\mathrm{mm})$ & $\hat{\mathrm{y}}=0,456+0,0226 \times$ ordem de postura & 0,345 \\
Comprimento do ovo $(\mathrm{mm})$ & $\hat{\mathrm{y}}=21,63+0,0330 \times$ ordem de postura & 0,254 \\
Dias para eclosão & $\hat{\mathrm{y}}=21,23-1,09 \times$ ordem de postura & 0,318 \\
\hline
\end{tabular}

O peso do ovo apresentou correlação negativa e significativa $(\mathrm{P}<0,1)$ com a ordem de postura, sendo os primeiros ovos com maior peso em relação aos demais, o que, segundo Kozlowski e Ricklefs (2010), ocorre devido ao fato de os primeiros ovos possuírem gemas mais pesadas.
Peso do ovo apresentou correlação positiva e significativa $(\mathrm{P}<0,01)$ com as variáveis, comprimento e largura do ovo. Essa correlação, segundo Campos et al. (2005), auxilia nos manejos com os ovos, reduzindo a realização de mensurações do comprimento e da largura do ovo, diminuindo consideravelmente a 
manipulação dos ovos e, consequentemente, as contaminações, podendo usar somente o peso do ovo, uma medida menos invasiva.

O tempo de eclosão apresentou correlação negativa $(\mathrm{P}<0,01)$ com a ordem de postura, e o tempo de incubação dos últimos ovos foi menor que os primeiros. Vinuela (1997) explica que esse comportamento ocorre devido à comunicação sonora entre os embriões, o que reduz o tempo de incubação dos últimos ovos.

\section{CONCLUSÃO}

A reprodução de psitacídeos em cativeiro pode se tornar uma ferramenta importante para a conservação de populações na natureza e ameaçadas de extinção. Os resultados encontrados neste estudo suportam a conclusão de que a dieta formulada conseguiu suprir as necessidades nutricionais das calopsitas na fase reprodutiva e não afetou a qualidade e a fertilidade dos ovos.

\section{REFERÊNCIA}

ALLGAYER, M.C.; CZIULIK, M. Reprodução de psitacídeos em cativeiro. Rev. Bras. Reprod. Anim., v.31, p.344-350, 2007.

CAMPOS, M.S.; CARVALHO, I.D.; FILHO, A.C.B. et al. Estimativa de correlações entre medidas morfométricas, peso do ovo e peso de filhotes de emas criados em cativeiro. Cienc. Rural, v.35, p.678-683, 2005.

CARCIOFI, A. C. Avaliação de dieta à base de sementes e frutas para papagaios (Amazona sp): determinações da seletividade dos alimentos, consumo, composição nutricional, digestibilidade e energia metabolizável. 1996. 104 f. Dissertação (Mestrado em Zootecnia) Faculdade de Medicina Veterinária e Zootecnia, Universidade de São Paulo, São Paulo, 1996.

CHRISTIDIS, L. SCHODDE, R.; SHAW, D.D. et al. Relationships among the Australo-Papuan parrots, lorikeets, and cockatoos (aves: Psittaciformes): protein evidence. Condor, v.93, p.302-317, 1991.

FASENKO, G.M.; HARDIN, R.T.; ROBINSON, F.E. Relationship of hen age and egg sequence position with fertility, hatchability, viability and preincubation embryonic development in broiler breeders. Poult. Sci., v.71, p.1374-1383, 1992.
FORSHAW, J.M.; COOPER, W.T. Parrots of the world. Melbs: Lansdowne Press, 1981. v.2, $616 \mathrm{p}$.

GOWLAND, D.J. Captive Amazon parrots and their diet: a study on reproductives sucess. Queanbeyan: Priam Psittaculture Centre Research \& Breeding, 2014. 26p.

HAGEN, M. Comparing two feeding methods in an outdoor aviary. Canadian: Parrot Sumporium, 1994.

KOZLOWSKI, C.P., RICKLEFS, R.E. Egg size and yolk steroids vary across the laying order in cockatiel clutches: a strategy for reinforcing brood hierarchies? Gen. Comp. Endocrinol., v.168, p.460-465, 2010.

MACHADO, P.A.R.; SAAD, C.E.P. O futuro das rações para aves ornamentais e silvestres no Brasil. Aves Rev. S. Am. Ornitofilia, v.3, p.37-40, 2000.

MARQUES, D.C; VOLTARELLI, E.M; PACHALY, J.R. Análise do comportamento alimentar de araras do parque municipal do ingá - Maringá, PR. Arq. Ciênc. Vet. Zootec., v.12, p.109-113, 2009.

MESQUITA, M.A. Fatores que afetam o desenvolvimento de embriões de frangos de corte durante a incubação. 2011. 41f. Seminário (Mestrado em Ciência Animal) - Escola de Veterinária, Universidade Federal de Goiás, GO.

ROBINSON, F.E.; HARDIN, R.T.; ROBINSON, N.A. et al. The influence of egg sequence position on fertility, embryo viability and embryo weight in broiler breeders. Poult. Sci., v.70, p.760-765, 1991

SAAD, C.E.P. Avaliação de alimentos $e$ determinação das necessidades de proteína para manutenção de papagaios-verdadeiros (Amazona aestiva). 2003. 160f. Tese (Doutorado em Zootecnia) - Escola de Veterinária, Universidade Federal de Minas Gerais, Belo Horizonte, MG.

SAAD, C.E.P.; FERREIRA, W.M.; BORGES, F.M.O. et al. Avaliação do gasto e consumo voluntário de rações balanceadas e semente de girassol para papagaios-verdadeiros (Amazona aestiva). Ciênc. Agrotec., p.1176-1183, 2007. 
SOMENZARI, M. Taxonomia do complexo Pyrrhura lepida (aves: Psittacidae). 2011. Dissertação (Mestre em Zoologia) - Instituto de Biociências, Universidade de São Paulo, São Paulo, SP.

TORLONI, C.E.C. Criação de calopsitas. São Paulo: Ivaiporã, 2001, 80p.

UBUKA, T.; BENTLEY, G.E. Neuroendocrine control of reproduction in birds. hormones and reproduction of vertebrates in birds. [s.1.]: [s.n.], 2011. p.1-25.
ULlREY, D.E.; ALLEN, M.E.; BAER, D.J. Formulated diets versus seed mixtures for psittaccines. J. Nutr. v.121, p.193-205, 1991.

VIÑUELA, J. Laying order affects incubation duration in the black kite (Milvus migrans): counteracting hatching asynchrony. Auk, v.114, p.192 199, 1997.

WHITE, N.E. et al. The evolutionary history of cockatoos (aves: Psittaciformes: Cacatuidae). Mol. Phylogenet. Evol., v.59, p.615-622, 2011. 